REVIEW

\title{
A Literature Review of Placenta Accreta Spectrum Disorder: The Place of Expectant Management in Ethiopian Setup
}

\author{
Yifru Berhan $^{1^{*}}$, Tadesse Urgie ${ }^{1}$
}

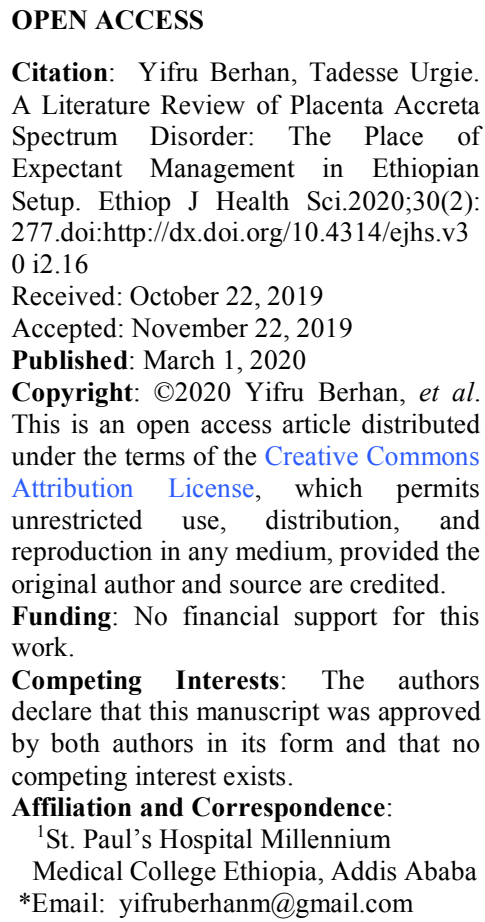

\begin{abstract}
In the last three to four decades, the increasing caesarean delivery rate has contributed to several fold increment in the incidence of placenta accreta spectrum disorders globally. Placenta accreta spectrum with its subtypes (accreta, increta and percreta) is one of the devastating obstetric complications. As a result, it is the commonest indication for peripartum hysterectomy and common cause of severe maternal morbidity. However, in recent years, there is a growing interest in and practice of expectant management either to minimize emergency hysterectomy related maternal complications or to preserve the fertility potential of a woman with an intact uterus. A large body of observational research findings has demonstrated the success rate of expectant management in many of well selected cases. Similarly, the experience on delayed hysterectomy was encouraging in order to have less hemorrhage. For the best success of placenta accreta spectrum management, multidisciplinary team approach, antenatal diagnosis and managing such cases in a hospital with center of excellence has been strongly recommended. This literature review provides a robust synthesis of up-to-date knowledge and practice on the challenges and successes of placenta accreta spectrum disorders management. The currently practiced management options in the high and middle income countries are also summarized under seven categories. Therefore, the purpose of this review was to shed light on the applicability of the PAS disorder management modalities in our setup.
\end{abstract}

\section{INTRODUCTION}

Placenta accreta spectrum (PAS), first described in 1937 (1), refers to the pathologic invasion of the placental trophoblasts to the myometrium and beyond, which was formerly known as morbidly adherent placenta with subtypes described as accreta (adheres to the myometrium), increta (invades deep to the myometrium) and percreta (the invasion reaches to the uterine serosa and beyond) (2).

Why the placenta gets infiltrated deep to the myometrium is not exactly known. Taking the strong association of PAS with uterine scar, defective decidualization at the endometrium-myometrium interface is usually attributed to its occurrence (3), but that does not 
exclusively explain the whole picture. Infrequently, PAS occurs in the first pregnancy. The rare variety of PAS which one of the authors experienced is the growth of the significant part of the placenta in the utero-vesical pouch passing through the uterine window of caesarean section (CS) scar while the fetus and part of the placenta was on the inside wall of the placenta. Placenta percreta extending beyond the uterine surface is not uncommon.

The global incidence of PAS is not known because of the paucity of data from developing countries. In the United States of America (US), for instance, the incidence of PAS rose from 1 in 2510 to 1 in 4017 between 1970s and 1980s (4) to 1 in 272 in 2016 (5), which is about 10-15-fold increment in the last three to four decades. Its incidence was much higher in women with placenta previa and/or scarred uterus $(6,7)$. The finding of anterior low lying or major placenta previa with a previous CS scar was highly indicative of the possibility of PAS, which is still a reminder that such cases require thorough ultrasound screening by an expert in the field starting from 18 weeks' gestation $(5,6)$.

In general, the increasing number of $\mathrm{CS}$ delivery across the world is highly incriminated for the progressively increasing incidence of placental adherence (8). A meta-analysis of 11 case-control and 5 cohort studies showed about 2-fold increased risk of the PAS disorder after CS (9). Women with three or more uterine CS scar were more than 10 times at higher risk of PAS than women with single uterine scar, which indicates the increased risk of PAS as the number of CS scar increases.

In agreement with this finding, a systematic review reported the incidence of PAS as 3.3\%-4\% in women with placenta previa with no CS scar and $50-67 \%$ in women with three or more CS scars (10). About a decade back, another study reported that women presenting with placenta previa and prior $\mathrm{CS}$, the incidence of PAS was $3 \%, 11 \%, 40 \%$, $61 \%$ and $67 \%$ for one, two, three, four, and five or more CS deliveries, respectively (11). Other risk factors attributed to PAS are also related to surgical and infectious injuries, which potentially can cause scar to the uterine wall (previous history of PAS, current placenta previa, previous myomectomy, metroplasty, endometrial ablation, Asherman's syndrome, excised uterine polyp, repaired uterine perforation or rupture, endometrial curettage and previous endomtritis) $(5,8)$.

The immediate common complication of PAS is postpartum hemorrhage (PPH). Some call PAS the 'nightmare' of obstetricians (because of the massive hemorrhage encountered during an attempt of manual removal or during surgical excision of PAS involving extrauterine organs, and during caesarean hysterectomy) (12). The very severe complications (moribund hemorrhagic shock during delivery and uterine rupture before the onset of labor and usually early in pregnancy) are commonly encountered in women with placenta percreta (13-15). As a result, PAS is known to increase the relative risk of maternal death (16), but varies with the time of detection and subsequent interventions. PAS is also a common indication for peripartum hysterectomy. For instance, in the US and Australia, peripartum hysterectomy was the indication for $38 \%$ and $70 \%$ of peripartum hysterectomies, respectively (17).

The progressively increasing incidence and the challenge in its management of the day-to-day practice is the main reason that urges the authors to go for in-depth review of literature and discuss the management challenges and the possibility of expectant management in our setup when conditions are against with hysterectomy or a woman badly need preserving her uterus. Of note, planned or emergency caesarean hysterectomy has been the standard practice globally, and in our practice too, for all types of PAS with irremovable placenta or intractable $\mathrm{PPH}$.

However, there is a growing interest in and practice of expectant management of PAS primarily to minimize fatal and highly morbid complication associated with immediate hysterectomy, and secondly to preserve the uterus when there is indication and preconditions fulfilled. Among others, the nearly a quarter success rate of pregnancies (18) after expectant management has motivated many obstetricians to consider the expectant management as one of the treatment modalities. Therefore, the purpose of this review is to provide an up-to-date evidence on the place of expectant management and let our obstetriciangynecologists make an evidence based decision in the management of the growing and challenging PAS disorders. 


\section{ANTENATAL DIAGNOSIS OF PAS}

The diagnosis of PAS is suspected antenatally via imaging, and confirmed clinically usually during $\mathrm{CS}$, and occasionally with histopathologic examination of the hysterectomy or partially resected myometrial tissue. The antenatal diagnosis of PAS using imaging techniques is currently the gold standard and highly desirable to make a decision on the management plan and minimize the complications. From experience, it is known that the diagnosis of PAS is usually made intrapartum when exploration is done to spontaneously or with a simple cord traction undelivered placenta. Even in the developed world, three large case series studies have shown that $70 \%$ (19), 47\% (20) and $50 \%$ (21) of PAS cases were diagnosed during delivery.

Antenatal diagnosis of PAS with one of the imaging technique (transvaginal ultrasound, color Doppler or MRI) is possible, preferably in the second and third trimester (5), but the detection capacity depends on the skill and experience of the examiner and the index of suspicion clinicians put forth. Therefore, the absence of suggestive imaging findings does not necessarily preclude the high index of suspicion, particularly in women with known risk factors.

The ultrasonography finding in normal placental attachment is hypoechoic space between the placental body and the myometrium. In the morbidly adherent placenta, among several ultrasound signs, it is common to find a loss of the normal hypoechoic zone between the myometrium and the placenta. Instead, multiple placental lakes/lacunae (some call it 'Swiss cheese' or 'moth-eaten' appearance within the placenta) and thinning of the utero-vesical wall in the anteriorly implanted placenta are usually seen (22). The same studies have reported that color flow Doppler imaging commonly shows the turbulent lacunar blood flow, an increase in sub-placental vascularity or vessels bridging the placenta to the uterine margin. Detail description of the diagnostic techniques and findings of PAS during imaging is beyond the scope of this article.

The sensitivity of ultrasound in the diagnosis of placental adherence is reported to be good, but less sensitive and specific to measure the depth of invasion and lateral extension. A systematic review and meta-analysis done in 2017 using the standardized ultrasound signs (using 2D gray-scale, 2D color Doppler or 3D color Doppler) have shown that the sensitivity and specificity of each was $97 \%$ (23).

Another tool to diagnose placental adherence is MRI, with the additional advantage of assessing the depth of invasion and lateral extension (6). Although some authors reported that MRI is less preferred and is often misleading when used as an adjunct to ultrasound (24), a metaanalysis has demonstrated that the overall detection of PAS with ultrasound and MRI is almost similar and its importance in diagnosing posterior PAS, degree of invasion and myometrial lateral extension is superior to ultrasound (25). Assessing the depth and lateral extension has management significance (3); as discussed below, the different options take into account the extent of placental infiltration and adjacent organs involvement to consider either expectant or radical management.

It is noted that the sensitivity of MRI is better than Doppler ultrasound in detecting posteriorly implanted placenta, but the specificity of Doppler is much higher than the MRI in anteriorly and laterally implanted placenta with myometrial invasion. Since the majority of uterine scars are anterior, thereby the likelihood of PAS is more in anteriorly implanted placenta, and taking the cost and expertise, the importance of MRI is limited to only cases of diagnostic challenge. There are also some biomarkers of PAS disorders (alphafetoprotein, beta-human chorionic gonadotropin and pregnancy-associated plasma protein A) whose benefit in the clinical setting is not yet well substantiated.

Prognostic wise, a large body of observational studies has shown the reduced risk of maternal morbidity and mortality in antenatally diagnosed PAS disorders; it gives an opportunity for essential preparations and precautions, including multidisciplinary team management, making a decision to the time of delivery and providing prophylactic medical and surgical interventions (21,26-28). Management of accidently found PAS during delivery were

DOI: http://dx.doi.org/10.4314/ejhs.v30i2.16 
reported as commonly increasing the risk of lifethreatening complications. Among others, massive hemorrhage and blood transfusion requirement were very common in women who were diagnosed to have PAS in the third stage of labor as compared to antenatally diagnosed PAS cases $(21,26,28-30)$.

A report from Finland has shown that the range of blood loss among women who were diagnosed to have PAS antenatally and during delivery was $100-15,000 \mathrm{ml}$ and $2500-17,000 \mathrm{ml}$, which required as high as 27 and 31 units of blood transfusion, respectively (28). Similarly, blood transfusion requirement in antenatally and intrapartum diagnosed PAS cases (increta and percreta) were $59 \%$ and $94 \%$, respectively; the range of blood loss in the two groups was also statistically significant $(250-10,514 \mathrm{ml}$ in antenatally diagnosed versus $1500-24,000 \mathrm{ml}$ in unsuspected cases) (21).

In general, the antenatal diagnosis of PAS gives an opportunity not to go for forcible attempt of removal of the placenta, and get prepared for multidisciplinary team management thereby help reduce the blood loss and other complications. The multidisciplinary management has been shown to reduce the blood loss and improving the maternal and perinatal outcomes $(6,27)$. Equally important, planned CS can be performed before the onset of labor.

The antenatal diagnosis of PAS is also an advantage to administer corticosteroid, cross-match blood and counsel the woman still on the possibility of hysterectomy in a condition expectant management is favored. It is an opportunity to provide the basic information to women who preferred preserving her uterus to be aware of the increased risk of immediate complications (early and late $\mathrm{PPH}$, infection, uterine necrosis, delayed hysterectomy, acute renal failure, coagulopathy, pulmonary embolism, sepsis) and long term complications of preserving it (recurrence of PAS, fistula, uterine window, pelvic adhesion and many more). Furthermore, it is an important evidence to refer the woman to a center where there are experts in both surgical and expectant management of PAS $(27,30)$.

The bottom line is that every pregnant woman with a previous uterine scar and/or diagnosed to have placenta previa need to be offered in-depth imaging evaluation for PAS, preferably by a radiologist.

\section{MAKING DECISION ON EXPECTANT MANAGEMENT OF PAS}

Although expectant management has been practiced since 1986 (31), it is still limited to certain areas and done for certain indications. In literature, expectant and conservative management is interchangeably used when the uterus is preserved after a morbidly adherent placenta is conservatively managed, usually with the intention of preserving the fertility. Conservative, literally, is to mean that the surgical interventions will not end up with removal of the uterus. Therefore, in the article, expectant management is consistently used.

The most common indications for expectant management of PAS are preserving the natural fertility, delaying hysterectomy procedure or when the risk of bleeding due to radical surgery is assumed to outweigh the expectant management, particularly in case of triple or quadruple combination of complications (PAS, previa, adhesion and hemorrhagic shock), which all are not uncommon in pregnancy after previous CS (6). Therefore, expectant management is not only to preserve the uterus but also to prevent lifethreatening complications associated with manual placenta removal attempts or emergency caesarean hysterectomy (2).

Placenta percreta-related infiltration to the adjacent structures (usually bladder, rarely other visceral organs) is another major reason not to attempt removal of the placenta and make a decision on expectant management. In such condition, going for primary hysterectomy or excision of the placenta from its extrauterine dense attachment is likely to result in torrential bleeding that may endanger the life of the woman (18).

Specifically, when the urinary bladder invasion by the placenta is detected on ultrasound examination, preoperative cystoscopy and placement of prophylactic ureteral stents have been recommended (32). Similarly, for all major extrauterine invasions of the placenta, a multidisciplinary team approach (at least involving experienced obstetrician, urologist, anesthesiologist 
and neonatologist) can minimize the anticipated massive hemorrhage and further complications.

In antenatally diagnosed PAS, the surgical management options with different scenarios have to be exhaustively discussed among the managing team for the benefit of the doubt and making everybody on board during the procedure and the postpartum follow-up period. Involving the woman in the decision making is always a wise practice as there are conditions that make the caesarean hysterectomy a must while the plan is to go for expectant management.

Secondly, the caesarean hysterectomy for PAS may complicate with massive hemorrhage requiring blood transfusion, injury to the bladder, ureter and bowel, and postpartum infection $(33,34)$. As noted earlier, the requirement of many units of blood, the conservative and radical surgical techniques, the increased likelihood of having as well placenta previa and premature delivery, and increased chance of admission to the intensive care units (ICU) warrant the management of PAS in a hospital which has developed the excellence in handling similar cases (5). Specifically, if placenta percreta is diagnosed antenatally, all efforts should be made to transfer the woman to a higher center, as it is likely to seriously complicated with (19).

Although antenatal diagnosis of PAS has multiple advantages, there is no accessible randomized clinical trial that assessed the timing of delivery. One guideline recommends a similar approach to placenta previa (planned CS if late at 37 weeks' gestation) (6). However, the strong association of PAS with placenta previa may let dictate earlier termination of pregnancy if there is active bleeding due to the latter problem. Otherwise, at present, there is no good evidence that supports termination of pregnancy in the second trimester for the suspected PAS of any degree (5). In general, an expectant management decision is made when the fertility need is high or hysterectomy carries an unacceptably high risk to the survival of the mother.

\section{MANAGEMENT OPTIONS FOR WOMEN WITH PAS}

Our literature review has identified several options of management in women with PAS. Each option has its own risks and benefits. The choice of the PAS management options depends on the skill of the surgeon to perform hysterectomy in a bloody condition, the hemodynamic status of the patient to tolerate anesthesia and further blood loss, the need of preserving the uterus, the ability to secure hemostasis while the placenta is in situ, the warranty of anticipated adherence to follow-up and the health facility setup for serial measurement of placental regression (35).

The summary of the different management options of PAS (as compiled from different literature to fit for the purpose) is presented below. All management options take third trimester pregnancy into consideration.

Option I (direct hysterectomy): Elective or emergency caesarean hysterectomy, without attempting removal of the placenta, is the usual practice in morbidly adherent placenta (36). In this scenario, the diagnosis of PAS can be made antenatal or intrapartum after vaginal or abdominal delivery. The decision is made straight to go for immediate hysterectomy.

To the authors' knowledge, in this country, for all manually irremovable PAS cases usually diagnosed in the third stage of labor, emergency hysterectomy is performed. Direct hysterectomy is also a preferred option elsewhere in women who completed their fertility, hemodynamically stable and when the setup enables performing emergency or elective hysterectomy.

A very recent single-center experience report from Canada has also shown that all women with PAS were provided caesarean hysterectomy. If hysterectomy is decided, both subtotal and total hysterectomy procedures are options $(21,37,38)$; the decision is made based on the hemodynamic status of the patient, absence or presence of major degree placenta previa and the skill of the surgeon. However, FIGO stated that caesarean hysterectomy is associated with $40 \%-50 \%$ increased risk of severe maternal morbidity. In women with placenta 
percreta, the mortality rates can be as high as $7 \%$, mainly due to pelvic organs injury and massive hemorrhage (2). The risks of mortality and severe morbidity increases in cases of placenta percreta managed with emergency caesarean hysterectomy. Although compared to other types of PAS, it is still at higher risk of complications, placenta percreta left in situ for delayed hysterectomy or spontaneous resorption has a better prognosis (39).

Option II (delayed hysterectomy): Delayed hysterectomy is preferred when 1) fertility and keeping the uterus is not a priority; 2) the case is not a good candidate for expectant management; and 3) the woman is not eligible or the setup is not conducive to perform an immediate hysterectomy. Specific to the latter, as noted earlier, it is common to diagnose placental adherence during CS with no preparation or capacity to go for a hysterectomy or to counsel the woman. In such circumstance, provided that there is no active bleeding or conservatively controlled, the abdomen can be closed, and the woman can be transferred to a center where multidisciplinary experts of a team are available.

Women diagnosed to have placenta percreta, in particular, can benefit a lot from delayed hysterectomy and multidisciplinary team management (40). Technically, after delivery of the fetus, the placenta is left in situ without attempting removal, by ligating and cutting the umbilical cord near the placental insertion, closing the uterine incision, and performing elective secondary hysterectomy 6-10 weeks after the delivery of the baby (41) unless complications warrant earlier delayed hysterectomy. A delay up to the first 24 hours (probably till the patient is in the hand of the right person) still belongs to option I management.

This option is also applicable to vaginal delivery by ligating and cutting the umbilical cord too short to let it stay inside the uterus, after the PAS is highly suspected with one of the imaging modalities. The advantage of delayed over the immediate hysterectomy is reduced blood loss and inadvertent injury to adjacent structures. Delayed hysterectomy is less risky in hemodynamically stable women with no sign of placental separation and/or no bleeding. Bladder injury is very common in emergency caesarean hysterectomy and placenta percreta cases $(40,42)$.

This option is not at all recommended in women whereby active bleeding could not be controlled, coagulopathy or infection has already developed or the risk is high. In case, the bleeding persists or starts to be in an uncontrollable state, it is likely that the placenta is partly separated and partly adherent. All efforts should be devoted to stop the bleeding, by applying conservative or radical surgical interventions.

As discussed below in other options, apart from administering Tranexamic acid, either conservative surgeries (like removal of the placenta in piecemeal with sponge forceps after vaginal delivery, with fingers after CS delivery, followed by the insertion of a uterine tamponade device or the application of uterine compression sutures and/or uterine vessels devascularization) or performing hysterectomy should not be delayed. This should be the management principle in options III-VI too.

Option III (expectant management with no attempt to remove the placenta and with no uterine devascularization or compression): Expectant management without attempting removal of the placenta encompasses administering prophylactic Tranexamic acid after clamping and cutting the cord too short $(6,43)$, closing the uterine incision in cases of CS, and observing for active vaginal bleeding. The intention is to preserve the uterus by expecting spontaneous placental resorption without uterine devascularization or compression intervention. Cases managed with this modality usually start to have vaginal bleeding after several days or weeks; when the placenta becomes necrotic, there is a chance of spontaneous separation and bleeding, which can be removed by ultrasound guided hysteroscopic resection. However, metallic curettage should not be attempted.

Like in option I, this option best fits for cases of PAS with no placental separation in the third stage of labor or no inadvertent or intentional disruption of the placenta. However, it can also be applied after partial placental separation if the Tranexamic acid or uterotonics (other than 
oxytocin) controls the active bleeding, and hemostasis is secured. A recent systematic review of placenta percreta cases has shown that the success of uterine preservation without any conservative surgical interventions was 39\%, which is lower than other types of PAS disorders, and with high maternal morbidity during the period of conservative management (42).

In one study, significant blood loss or uncontrolled bleeding was an indication for immediate hysterectomy after an expectant management decision was made with no attempt to remove the placenta in $31.4 \%$ (44). Particularly, in women with antenatal evidence of deep invasion, an attempt to remove the placenta was reported to be bloody, and it was a common indication for hysterectomy in 24 hours of delivery $(18,25,44)$.

In this kind of expectant management, what is most important is ascertaining the diagnosis of PAS (particularly, in cases of vaginal delivery) and close follow-up for active vaginal bleeding, infection and coagulopathy, and taking immediate action when complications encountered. In other words, this modality cannot be an option in women with active bleeding in either vaginal or CS delivery, in women with evidence of coagulopathy and uterine infection. In successful cases, the expectant management ends up with an empty uterus after spontaneous expulsion or assisted removal or complete resorption of the placenta.

Option IV (expectant management with conservative intervention to prevent $\mathbf{P P H}$ ): After delivery of the fetus and prophylactic Tranexamic acid is administered like in option III, one or two possible PPH prophylactic surgical or radiologic measures are performed. Depending on the setup and managing team preference, specific procedures selectively performed include uterine devascularization (major arteries ligation, arterial embolization, occlusion of the major arteries by placing intra-arterial balloon), applying uterine compression sutures, and inserting one of the intrauterine balloon tamponade devices (Bakri balloon, condom catheter, Foley catheter, Sengstaken-Blakemore oesophageal catheter, and the urological Rusch balloon) (45-47).
Applying these techniques is easier when the surgery is performed on elective base. Compression sutures and devascularization can be performed with the whole placenta is in situ or partly removed in both non-bleeding and actively bleeding uterus. Balloon tamponades are usually applied to arrest active bleeding. Among the balloon tamponades, one small case series study reported that inserting Bakri balloon prevented 16 out of 19 cases from hysterectomy by effectively controlling the bleeding from the placental bed because of the large volume it accommodates in (45). In our setting, the widely available condom catheter can be used.

Cervix as natural tamponade (by inverting the anterior or posterior lip of the cervix and suturing with the placental bed in the anterior or posterior wall of the uterus) was also reported from Egypt as safe, simple, time-saving and effective method for controlling PPH caused by placenta previa or placenta previa accreta (48). The same authors reported cervical tamponade with bilateral uterine artery ligation and removal of the placenta after a month on elective base as a safe alternative method to hysterectomy in those women who wish to preserve their fertility (49). In general, the devascularization procedures in option IV are not limited to the bilateral anterior division of internal iliac artery ligations like Shabana and colleagues 'stepwise approach', it entertains multiple alternative modalities.

Beyond the immediate actions, ultrasound guided hysteroscopic placental morcellation can be performed in between if there is transcervically accessible placental tissue which is amenable for resection. Hysteroscopic resection of retained placental tissue after some time was successful by avoiding hysterectomy in 11 out of 12 symptomatic women (50). It can be attempted under ultrasound guide in women with secondary bleeding due to significant placental tissue, which is accessible through the endometrial cavity. Such procedure is an advantage both to arrest the bleeding and shorten the placental resorption time.

In our common clinical practice, the successful removal of adherent placenta (usually 
accreta type) and controlling the bleeding with arteries ligation or compression methods or some other technique still belongs to this option.

Option V (expectant management with Triple-P procedure: Triple-P procedure is a variety of option IV. It is applicable in antenatally diagnosed PAS cases. The procedure includes 1) preoperative localization of the superior edge of the placenta; 2) pelvic devascularization by placing intra-arterial balloon catheters (at anterior division of the internal iliac arteries) before the surgery; and 3) placental non-separation with myometrial excision (limited excision of the myometrium with part of the placenta and closure of the defect to reduce the blood loss) (51). The temporal internal iliac balloon occlusion, as part of the Triple-P procedure or alone, however, is still highly controversial because of the increased risk of complications, including vessels rupture, ischemic injury and thrombus formation (52-55). As a result, FIGO recommended further study before this technique can be offered in the management of PAS disorders (2). PAS cases with extensive lateral or cervical invasion are not suitable for local resection. Otherwise, a bit similar surgical procedure was practiced in Argentina more than a decade before the Triple-P procedure.

Option VI (resection of all invaded myometrial tissue and expectant management): Resection of all placenta invaded myometrial tissue (some call it one-step conservative surgery) (55) is performed after delivery of the fetus and after the extent of placental invasion is grossly estimated. The procedure is completed by suturing the defect, securing hemostasis and administering Tranexamic acid, but without devascularization and other $\mathrm{PPH}$ surgical prophylactic measures.
The advantage of this procedure is almost entirely to remove the placental mass from the uterine wall. However, as the uterus is highly vascular organ during pregnancy, there may be massive hemorrhage, particularly in laterally implanted placenta and placenta percreta cases (42). When the excision is wide enough, the approximation will not be easier and is liable to uterine window formation. Thirdly, the extensive damage to the myometrial wall may increase the risk of scar dehiscence in subsequent pregnancies.

Option VII (manual removal of the placenta): In women with placenta accreta, actively bleeding, and cleavage plane appreciated, manual removal of placenta (if possible in totality, if not in piecemeal) accompanied by Tranexamic acid administration and intrauterine tamponade is lifesaving procedure. However, attempting manual removal of the placenta in cases of placenta increta and percreta is a very dangerous practice, which usually ends up with massive hemorrhage requiring emergency hysterectomy (46).

Many other authors also described such vigor as having devastating consequences to the mother by resulting in massive hemorrhage, disseminated intravascular coagulation and postpartum infection $(6,7,35,36)$. Therefore, if the diagnosis of PAS is made in the antenatal period and caesarean hysterectomy is decided, there is no need to attempt manual removal of the placenta $(6,35,36)$. Similarly, for PAS cases detected during CS, one should not go for forcible removal of the placenta; rather, involving the most senior person on what to do next is a wise decision. If there is no active bleeding, there is no need to rush for any action. 
Table 1: Review of case series studies (with $>30$ cases included) on expectant management of placenta accreta spectrum disorders

\begin{tabular}{|c|c|c|c|}
\hline $\begin{array}{l}\text { Authors, study period, } \\
\text { country }\end{array}$ & $\begin{array}{l}\text { Expectant } \\
\text { management } \\
\text { planned for }\end{array}$ & $\begin{array}{c}\text { Expectant } \\
\text { management } \\
\text { successful for }\end{array}$ & $\begin{array}{l}\text { Conservative surgical and radiological } \\
\text { interventions }\end{array}$ \\
\hline $\begin{array}{l}\text { Sentilhes L et al, 1993- } \\
2007, \text { France }^{\dagger}(18)\end{array}$ & 167 & $131(78.4 \%)^{\dagger}$ & $\begin{array}{l}\text { Placenta was left in situ partially in } 99 \text { and } \\
\text { entirely in 68; primary and secondary uterine } \\
\text { devascularizations were done in } 109 \text { and } 57 \text {, } \\
\text { respectively; methotrexate was given in } 21 \\
\text { cases. }\end{array}$ \\
\hline $\begin{array}{l}\text { Marcellin L et al, 2003- } \\
\text { 2017, France (44) }\end{array}$ & 107 & $86(80.4 \%)$ & $\begin{array}{l}\text { Bilateral hypogastric artery ligation for } 23 \text { cases; } \\
\text { pelvic arterial embolization for } 26 \text { cases; } \\
\text { preoperative balloon catheter was placed for } 7 \\
\text { cases. }\end{array}$ \\
\hline $\begin{array}{l}\text { El Gelany S et al, } 2017- \\
\text { 2018, Egypt (49) }\end{array}$ & 64 & $62(96.9 \%)$ & $\begin{array}{l}\text { Cervical tamponade with bilateral uterine artery } \\
\text { ligation for } 48 \text { cases; Postoperative uterine artery } \\
\text { embolization and removal of the placenta after a } \\
\text { month for } 10 \text { cases. }\end{array}$ \\
\hline $\begin{array}{l}\text { Timmerman S et al, } 1985- \\
2006, \text { multi-country }(60)\end{array}$ & 60 & $48(80 \%)$ & $\begin{array}{l}\text { Methotrexate was given in } 22 \text {; selective arterial } \\
\text { embolization for } 12 \text { and no intervention for } 26 \\
\text { cases. }\end{array}$ \\
\hline $\begin{array}{l}\text { Zhang C et al, 1998-2010, } \\
\text { China (61) }\end{array}$ & 54 & $50(92.5 \%)$ & $\begin{array}{l}\text { Methotrexate: IV injection for } 21 \text {, success in } 17 \\
\text { (Group 1); multipoint placental injection for } 33 \text {, } \\
\text { success in all (Group II). }\end{array}$ \\
\hline $\begin{array}{l}\text { Bailit JL et al, 2008-2011, } \\
\text { US }^{\dagger \dagger}(20)\end{array}$ & 158 & $48(30.4 \%)$ & $\begin{array}{l}\text { Balloon tamponade for } 5 \text {, B-Lynch suture for } 3 \text {, } \\
\text { two or more uterotonics other than oxytocin for } \\
17 \text { and artery ligation for } 2 \text { cases. }\end{array}$ \\
\hline $\begin{array}{l}\text { Palacios-Jaraquemada JM } \\
\text { et al, 1995-2003, } \\
\text { Argentina (62) }\end{array}$ & 68 & $50(73.5 \%)^{\dagger \dagger}$ & $\begin{array}{l}\text { Uterine devascularization by artery ligation for } \\
57 \text { and B-Lynch suture for } 5 \text { and local square } \\
\text { sutures for } 15 \text { cases. }\end{array}$ \\
\hline $\begin{array}{l}\text { Mei J et al, 2010-2013 } \\
(63)\end{array}$ & 177 & $159(90 \%)$ & Arterial embolization for all cases. \\
\hline $\begin{array}{l}\text { Mei J et al, 1980-2012 } \\
(63)\end{array}$ & 76 & $48(63 \%)$ & $\begin{array}{l}\text { Uterus preserving surgery for all (hemostatic } \\
\text { sutures and arterial ligation) }\end{array}$ \\
\hline $\begin{array}{l}\text { Mei J et al, 2007-2012 } \\
(63)\end{array}$ & 42 & $33(79 \%)$ & Artery occlusion balloon for all \\
\hline $\begin{array}{l}\text { Matsuzaki S et al, 1990- } \\
2016^{\ddagger}(42)\end{array}$ & 68 & $42(61.8 \%)$ & $\begin{array}{l}\text { Prophylactic, therapeutic uterine artery } \\
\text { embolization and both for } 33,11 \text { and } 3 \text { cases, } \\
\text { respectively; methotrexate for } 27 \text { and etoposide } \\
\text { for } 3 \text { cases. }\end{array}$ \\
\hline Clausen C et al, 2013*(40) & $53{ }^{5}$ & $32(60.4 \%)$ & $\begin{array}{l}\text { Arterial embolization for } 23 \text {, embolization and } \\
\text { balloon occlusion for } 4 \text { and balloon occlusion } \\
\text { only for } 16 \text { cases. }\end{array}$ \\
\hline $\begin{array}{l}\text { Pather S } \\
\text { et al, 1995-2012 (64) }\end{array}$ & 60 & $36(60 \%)$ & $\begin{array}{l}\text { Pelvic embolization for } 28 \text {, methotrexate for } 20 \text {, } \\
\text { both for } 11 \text { and other procedures for } 13 \text { cases. }\end{array}$ \\
\hline
\end{tabular}

${ }^{\dagger}$ From 25 university hospitals; 10 of 18 placenta percreta cases were successful. "TFrom 25 hospital. ${ }^{\dagger} 24$ became pregnant. ${ }^{\dagger} 10$ became pregnant in 3 years. ${ }^{\ddagger}$ Review. All were placenta percreta cases. ${ }^{\int}$ Placenta left in situ $(\mathrm{n}=36)$ and local resection done $(\mathrm{n}=17)$ 


\section{COMMENT}

Since all PAS management options are not yet well substantiated with well-designed randomized clinical trials data, option I (when conditions allow) and option II (buying some time for the patient to be hemodynamically stable, uterine and placental size shrunk) are plausible decisions that need to be made for a woman who completed her family or have another reason that precludes her from expectant management. Option III cannot be planned without adequate preparation for immediate surgical intervention and blood transfusion. In our setup, option III shall be considered watchfully in tertiary centers with adequate blood products, adult ICU as a backup and optimal laboratory setup for follow-up.

Option IV may fit best for our tertiary setting when expectant management is antenatally decided; at least surgical devascularization or compression sutures can be applied. Option VI and VII are the riskiest in terms of experiencing massive hemorrhage, and are not a good choice for us as there is meagre access to blood products for transfusion in almost all health facilities. Option VII, in particular, usually ends up with salvage hysterectomy and life threatening condition in women with deep placental invasion.

Selecting the appropriate candidate for expectant management, to the best with prenatal diagnosis and ahead planning the type of surgery, and involving the locally available experts in the field, is a pragmatic decision $(26,28)$. By any standard, preserving the uterus never ever be with the expense of significant blood loss that may endanger the life of the mother. ACOG also recommends expectant management only for carefully selected cases with adequate counseling on potential risks (5).

In case expectant management (option IIIVI) is decided, prophylactic antibiotic (amoxicillin or clindamycin) (2) and Tranexamic acid administration should be routine. The recommendation on prophylactic Tranexamic acid is based on the observed significant reduction of hemorrhage during CS (56), and with the assumption that if placenta starts separating spontaneously, it can reduce the blood loss.
The resorption of placenta left in situ is assessed by weekly measuring the placenta mass, determining the beta-human chorionic gonadotropin (beta-hCG) levels, and the uteroplacental arterial circulation using Doppler ultrasound. It should also be well noted that betahCG may be undetectable while the placenta mass is still there (2). Therefore, the drop of beta-hCG level should be complemented by transvaginal unmeasurable placental mass. The follow-up should also give emphasis to an assessment of the hematologic profile for coagulopathy and infection.

Spontaneous resolution of the placenta percreta and increta may take 1-12 months. Early and late PPH is the most common complication of expectant management (18). Other less common complications in the postpartum period include DIC, endomyometritis, and sepsis. In subsequent pregnancies, there is an increased risk of recurrent PAS, PPH, uterine rupture, and peripartum hysterectomy (57-59).

In general, expectant management of PAS is not a decision to be made because the woman requests preserving her uterus. Risks have to be weighed from a different perspective. It is highly recommended that such decision be made and the whole course of treatment and follow-up is in a tertiary center (26). This is because CS may require hysterectomy; expectant management may require some advanced surgical techniques to minimize complications, interventional radiology, and methotrexate administration although its importance is still uncertain $(5,42)$. Furthermore, to have a better prenatal diagnosis, to provide blood transfusion, and to have close biochemical and imaging follow-up for placental status and complications, referring such cases to a tertiary center is highly recommended.

Large case series studies (which had included $>30$ cases of expectant management) are summarized in Table $1(18,20,40,42,44,49,62,60$, $61,63,64)$ to show the outcomes of uterine preserving interventions. As there were plenty of success stories in non-percreta cases, in terms of avoiding hysterectomy, there were also failures, primarily due to serious complications requiring immediate and delayed hysterectomy. In all these case series studies, the most challenging complication was $\mathrm{PPH}$, which was actually the

DOI: http://dx.doi.org/10.4314/ejhs.v30i2.16 
major indication for both primary and secondary hysterectomies after a decision was made on expectant management.

In the largest case series study with the highest success rate of expectant management (78.4\%), more than half (51.5\%) developed PPH, and $\mathrm{PPH}$ was the indication for all primary and $44.4 \%$ of secondary hysterectomies (18). The second reason for the high failure rate of the expectant management was the type of PAS being placenta percreta. In general, the success rate of expectant management in women with placenta percreta was not as high as accreta and increta $(40,42,65)$; failures were reported even after 9 months of expectant management (40).

In the majority of the included studies, uterine devascularization was the common procedure, and the proportion of uterine preservation was encouraging to do more. However, when the intention of preserving the uterus is maintaining fertility, the success of the expectant management is best measured by the number of pregnancies reaching third trimester. A follow-up study by including 96 cases who were managed expectantly concluded that expectant treatment did not appear to compromise the subsequent fertility or obstetric outcome; 24 women were able to achieve 34 pregnancies. Of these, 21 were live births (66). Another study, which followed 68 cases for 10 years after expectant management, reported 272 deliveries, but with more than 15 -fold increased risk of PAS recurrence (65).

With regard to the use of methotrexate in the PAS expectant management, as there is no clinical trial that verifies its importance, many authors are not recommending it, primarily by taking into consideration the biology of the placenta. In other words, although there is a long experience in its use for placental tissue left in situ and thought to induce placental necrosis and rapid involution, currently, it is not recommended $(2,35,42)$. A recent systematic review has also shown no statistically significant difference between chemotherapy received and control groups (42). The argument is that since the fetal placental circulation is interrupted and the placentas are usually somehow aged, trophoblastic cells proliferation will no more be active at and near term for the methotrexate to act $(2,5)$.

However, there are some success stories (spontaneous placental expulsion and faster complete involution) reported from the case series studies with methotrexate administration (67-69). A recent published study from China (including 54 cases for expectant management) has reported a success rate of $92.5 \%$ by administering methotrexate intravenously or local multi-point injection under ultrasound guidance, with 100\% success in the latter group (61).

Of note, the potential side effect of methotrexate (including its safety margin for lactating mother) in the immediate postpartum women is not well known although there are few clearly associated complications, including massive hemorrhage, endomyometritis, sepsis (68), and one maternal death (21). There is no as well consensus on the optimal dose and the route of administration (some used trans-umbilical, others intramuscular). In one review, the dose of methotrexate ranged from $50 \mathrm{mg}$ to more than $300 \mathrm{mg}$ with variable rates of success (42). In short, till a good scientific evidence comes with randomized clinical trial, whether to include it in the expectant management package of PAS or totally exclude it, the decision is left to the managing team.

The place of uterotonics in the management of PAS is also controversial. Some authors and guidelines recommended (61), but others are against, fearing the possible risk of partial placental separation and massive hemorrhage (70). In the largest case series study (18), all women were given uterotonics. In another study, one or more uterotonics (other than oxytocin) were also given in 33 cases (20).

In conclusion, the success rate of expectant management was better with one of the adjuvant interventions like arterial ligation, compression sutures and partial resection of the placenta, which can be practiced in our tertiary centers. The recently (2019) reported a high success rate of expectant management from Egypt with triple intervention (cervical tamponade, uterine devascularization and removal of the placenta within 32-72 days after delivery) (49) is a new experience, which may be considered in selected 
cases. Expectant management should be considered when a woman is ineligible for primary hysterectomy and will not be harmed much by the complications related to the placenta left in situ.

\section{KEY POINTS}

- Since PAS shows an increasing trend with increasing CS rate globally, a high index of suspicion during the antenatal period makes the managing team better prepared for its early diagnosis and elective intervention.

- Whenever a woman is antenatally diagnosed to have placenta previa in scarred uterus, she should be referred to an experienced radiologist with high index of suspicion to PAS.

- For antenattally diagnosed PAS cases, elective caesarean hysterectomy is still the safest option for the majority of PAS cases not later than 37 weeks of gestation.

- There is a place of expectant management in Ethiopian setup at tertiary level for appropriately selected cases after developing a management protocol and making a multidisciplinary team management preparation.

- Applying one or two of the four conservative surgical procedures (uterine devascularisation, compression sutures, uterine balloon tamponade, partial myometrial resection) or arterial embolization, and administering Tranexamic acid to all can increase the chance of uterine preservation.

- All intrauterine pregnancies after expectant management of PAS should be considered as having another PAS until proved otherwise.

\section{REFERENCES}

1. Irving C, Hertig AT. A study of placenta accreta. Surgery, Gynecology \& Obstetrics, 1937; 38(6): 1088-1200.

2. Sentilhes L, Kayem G, Chandraharan E, Palacios-Jaraquemada J, Jauniaux E. FIGO consensus guidelines on placenta accreta spectrum disorders: Conservative management. Int J Gynecol Obstet, 2018; 140: 291-298.
3. Jauniaux E, Collins S, Burton GJ. Placenta accreta spectrum: Pathophysiology and evidence based anatomy for prenatal ultrasound imaging. Am J Obstet Gynecol, 2018; 218: 75-87.

4. Wu S, Kocherginsky M, Hibbard JU. Abnormal placentation: twenty-year analysis. Am J Obstet Gynecol, 2005; 192:1458-61.

5. American College of Obstetricians and Gynecologists (ACOG) and Society for Maternal-Fetal Medicine. Obstetric care consensus. Placenta accreta spectrum. Obstet Gynecol, 2018; 132(6): e259-275.

6. Jauniaux ERM, Alfirevic $Z$, Bhide AG, Belfort MA, Burton GJ, Collins SL, et al. Placenta Praevia and Placenta Accreta: Diagnosis and Management. Green-top Guideline No. 27a. BJOG, 2018; https://doi.org/10. 1111/1471-0528.15306.

7. Fitzpatrick KE, Sellers S, Spark P, Kurinczuk JJ, Brocklehurst P, Knight M. Incidence and risk factors for placenta accreta/increta/percreta in the UK: a national case-control study. PLoS One, 2012; 7: e52893

8. Eshkoli T, Weintraub AT, Sergienko R, Sheiner E. Placenta accreta: risk factors, perinatal outcomes, and consequences for subsequent births. Am J Obstet Gynecol, 2013; 208: 219. E1-7.

9. Marshall $\mathrm{NE}, \mathrm{Fu} \mathrm{R}$, Guise JM. Impact of multiple cesarean deliveries on maternal morbidity: a systematic review. Am J Obstet Gynecol, 2011; 205: 262. E1-8.

10. Klar M, Michels KB. Cesarean section and placental disorders in subsequent pregnancies-a meta-analysis. $J$ Perinat Med, 2014; 42: 571-83.

11. Silver RM, Landon MB, Rouse DJ, Leveno KJ, Spong CY, Thom EA, et al. National Institute of Child Health and Human Development Maternal-Fetal Medicine Units Network. Maternal morbidity associated with multiple repeat cesarean deliveries. Obstet Gynecol, 2006; 107:1226-32.

12. Choudhary D, Nigam A, Yadav R, Choudhary S, Raghunandan C. Placenta Accreta: 
Obstetrician's Nightmare; A Case Series of Seven Patients. NJOG, 2012; 7(3): 56-58

13. Sun JN, Zhang BL, Yu HY, Zhang Q. Spontaneous uterine rupture due to placenta percreta during pregnancy. Am J Emerg Med, 2016; 34: 1918.e1-3.

14. Hornemann A, Bohlmann MK, Diedrich K, Kavallaris A, Kehl S, Kelling $\mathrm{K}$, et al. Spontaneous uterine rupture at the $21^{\text {st }}$ week of gestation caused by placenta percreta. Arch Gynecol Obstet, 2011; 284: 875-8.

15. Brown JV $3^{\text {rd }}$, Epstein HD, Laflamme LA, Goldstein BH. First trimester placenta percreta with urinary bladder invasion. Int $J$ Gynaecol Obstet, 2016; 132: 102-3.

16. Usta IM, Hobeika EM, Musa AA, Nassar AH. Placenta previa-accreta: risk factors and complications. Am J Obstet Gynecol, 2005; 193: 1045-1049.

17. Cheng HC, Pelecanos A, Sekar R. Review of peripartum hysterectomy rates at a tertiary Australian hospital. Aust $N Z J$ Obstet Gynaecol, 2016;56(6):614-8.

18. Sentilhes L, Ambroselli C, Kayem G, Fernandez H, Perrotin F, Winer N, et al. Maternal outcome after conservative treatment of placenta accreta. Obstet Gynecol, 2010; 115:526-534.

19. Thurn L, Lindqvist PG, Jakobsson M, Colmorn LB, Klungsoyr K, Bjarnad_ottir RI, et al. Abnormally invasive placentaprevalence, risk factors and antenatal suspicion: results from a large populationbased pregnancy cohort study in the Nordic countries. BJOG, 2016; 123: 1348-55.

20. Bailit JL, Grobman WA, Rice MM, Reddy UM, Wapner RJ, Varner MW, et al. Morbidly adherent placenta treatments and outcomes. Obstet Gynecol, 2015; 125: 683-9.

21. Fitzpatrick KE, Sellers S, Spark P, Kurinczuk JJ, Brocklehurst P, Knight M. The management and outcomes of placenta accreta, increta, and percreta in the UK: a population-based descriptive study. BJOG, 2014; 121: 62-70.
22. Comstock $\mathrm{CH}$, Bronsteen RA. The antenatal diagnosis of placenta accreta. BJOG, 2014; 121:2.

23. Jauniaux E, Bhide A. Prenatal ultrasound diagnosis and outcome of placenta previa accreta after cesarean delivery: a systematic review and meta-analysis. Am $J$ Obstet Gynecol, 2017; 217: 27-36.

24. Einerson BD, Rodriguez CE, Kennedy AM, Woodward PJ, Donnelly MA, Silver RM. Magnetic resonance imaging is often misleading when used as adjunct to ultrasound in the management of placenta accreta spectrum disorders. Am $J$ Obstet Gynecol, 2018; 218: 618. E1-7.

25. D'Antonio F, Iacovella C, Bhide A. Prenatal identification of invasive placentaion using ultrasound: systematic review and metaanalysis. Ultrasound Obstet Gynecol, 2013: 42: 509-517.

26. Warshak CR, Ramos GA, Eskander R, Saenz CC, Kelly TF, Moore TR, et al. Effect of predelivery diagnosis in 99 consecutive cases of placenta accreta. Obstet Gynecol, 2010; 115: 65-9.

27. Shamshirsaz AA, Salmanian B, Fox KA, Diaz-Arrastia CR, Lee W, Baker BW, et al. Maternal morbidity in patients with morbidly adherent placenta treated with and without a standardized multidisciplinary approach. Am J Obstet Gynecol, 2015; 212: 218. E1-9.

28. Tikkanen M, Paavonen J, Loukovaara M, Stefanovic V. Antenatal diagnosis of placenta accreta leads to reduced blood loss. Acta Obstet Gynecol Scand, 2011; 90: 1140-6.

29. Bowman ZS, Manuck TA, Eller AG, Simons M, Silver RM. Risk factors for unscheduled delivery in patients with placenta accreta. $\mathrm{Am}$ J Obstet Gynecol, 2014; 210: 241.e1-6.

30. Chantraine F, Braun T, Gonser M, Henrich W, Tutschek B. Prenatal diagnosis of abnormally invasive placenta reduces maternal peripartum hemorrhage and morbidity. Acta Obstet Gynecol Scand, 2013; 92: 439-44.

31. Arulkumaran $\mathrm{S}, \mathrm{Ng} \mathrm{CS}$, Ingemarsson I, Ratnam SS. Medical treatment of placenta 
accreta with methotrexate. Acta Obstet Gynecologica Scand, 1986; 65: 285-286.

32. Norris BL, Everaerts W, Posma E, Murphy DG, Umstad MP, Costello AJ, et al. The urologist's role in multidisciplinary management of placenta percreta. BJU Int, 2016; 117:961-5.

33. Wright JD, Devine P, Shah M, Gaddipati S, Lewin SN, Simpson LL, et al. Morbidity and mortality of peripartum hysterectomy. Obstet Gynecol, 2010;115:1187-93.

34. Jauniaux E, Ayres-de-Campos D. FIGO consensus guidelines on placenta accreta spectrum disorders: introduction. Int $J$ Gynaecol Obstet, 2018;140:261-4.

35. Sentilhes L, Goffinet F, Kayem G. Management of placenta accreta. Acta Obstet Gynecol Scand, 2013; 92: 1125-1134.

36. Fox KA, Shamshirsaz AA, Carusi D, Secord AA, Lee P, Turan OM, et al. Conservative management of morbidly adherent placenta: expert review. Am J Obstet Gynecol, 2015; 213(6): 755-60.

37. Silver RM, Barbour KD. Placenta accreta spectrum: accreta, increta, and percreta. Obstet Gynecol Clin North Am, 2015; 42: 381-402.

38. Rossi AC, Lee RH, Chmait RH. Emergency postpartum hysterectomy for uncontrolled postpartum bleeding: a systematic review. Obstet Gynecol, 2010; 115(3): 637-44.

39. Allen L, Jauniaux E, Hobson S, PapillonSmith J, Belfort MA. FIGO consensus guidelines on placenta accreta spectrum disorders: nonconservative surgical management. Int $J$ Gynaecol Obstet, 2018;140(3):281-90.

40. Clausen C. Lonn L, Langhoff-Roos J. Management of placenta percreta: a review of published cases. Acta Obstet Gynecol Scand, 2014; 93:1858-1863.

41. Sawada M, Matsuzaki S, Mimura K, Kumasawa K, Endo M, Kimura T. Successful conservative management of placenta percreta: Investigation by serial magnetic resonance imaging of the clinical course and a literature review. J Obste Gynecol Res, 2016;42:281-90.
42. Matsuzaki S, Yoshino K, Endo M, Kakigano A, Takiuchi T, Kimura T. Conservative management of placenta percreta. Int $J$ Gynaecol Obstet, 2018;140(3):299-306.

43. American College of Obstetricians and Gynecologists. Practice Bulletin: Clinical Management Guidelines for ObstetricianGynecologists Number 76, October 2006: postpartum hemorrhage. Obstet Gynecol, 2006; 108:1039-47.

44. Marcellin L, Delorme P, Bonnet MP, Grange G, Kayem G, Tsatsaris V, et al. Placenta percreta is associated with more frequent severe maternal morbidity than placenta accreta. Am J Obstet Gynecol, 2018; 219(2): 193. E1-193.e9.

45. Pala S, Atilgan R, Baspinar M, Kavak EC, Yavuzkir S, Akyol A, et al. Comparison of results of Bakri balloon tamponade and caesarean hysterectomy in management of placenta accreta and increta: a retrospective study. J Obstet Gynecol, 2018; 38: 194-199.

46. Kayem G, Davy C, Goffinet F, Thomas C, Clément D, Cabrol D. Conservative vs extirpative management in cases of placenta accreta. Obstet Gynecol, 2004; 104(3):531-6.

47. Li GT, Li XF, Wu B, Li G. Longitudinal parallel compression suture to control postpartum hemorrhage due to placenta previa and accrete. Taiwan J Obstet Gynecol, 2016;55:193-197.

48. El Gelany S, Ibrahim EM, Mohammed M, Abdelraheim AR, Khalifa EM, Abdelhakium $\mathrm{AK}$, et al. Management of bleeding from morbidly adherent placenta during elective repeat caesarean section: retrospective record -based study. BMC Pregnancy Childbirth, 2019;19(1):106. Doi: 10.1186/s12884-019-2244-4.

49. El Gelany S, Mosbeh MH, Ibrahim EM, Mohammed M, Khalifa EM, Abdelhakium AK, et al. Placenta Accreta Spectrum (PAS) disorders: incidence, risk factors and outcomes of different management strategies in a tertiary referral hospital in Minia, Egypt: a prospective study. BMC Pregnancy Childbirth, 2019; 19(1):313. Doi: 10.1186/s12884-019-2466-5. 
50. Legendre G, Zoulovits FJ, Kinn J, Sentilhes L, Fernandez H. Conservative management of placenta accreta: Hysteroscopic resection of retained tissues. J Minim Invasive Gynecol, 2014; 21:910-913.

51. Teixidor Viñas M, Belli AM, Arulkumaran S, Chandraharan E. Prevention of postpartum hemorrhage and hysterectomy in patients with morbidly adherent placenta: A cohort study comparing outcomes before and after introduction of the Triple-P procedure. Ultrasound Obstet Gynecol, 2015;46:350355.

52. Bodner LJ, Nosher JL, Gribbin C, Siegel RL, Beale S, Scorza W. Balloon-assisted occlusion of the internal iliac arteries in patients with placenta accreta/percreta. Cardiovasc intervene radiol, 2006; 29: 354361.

53. Matsueda S, Hidaka N, Kondo Y, Fujiwara A, Fukushima K, Kato K. External iliac artery thrombosis after common iliac artery balloon occlusion during cesarean hysterectomy for placenta accreta in cervico-isthmic pregnancy. J Obstet Gynaecol Res, 2015; 41:1826-1830.

54. Wei X, Zhang J, Chu Q, Du Y, Xing N, Xu X, et al. Prophylactic abdominal aorta balloon occlusion during caesarean section: A retrospective case series. Int J Obstet Anesth, 2016; 27:3-8.

55. Palacios-Jaraquemada JM. Diagnosis and management of placenta accreta. Best Pract Res Clin Obstet Gynecol, 2008; 22:11331148 .

56. Simonazzi G, Bisulli M, Saccone G, Moro E, Marshall A, Berghella V. Tranexamic acid for preventing postpartum blood loss after cesarean delivery: A systematic review and meta-analysis of randomized controlled trials. Acta Obstet Gynecol Scand, 2016; 95:28-37.

57. Kayem G, Pannier E, Goffinet F, Grange G, Cabrol D. Fertility after conservative treatment of placenta accreta. Fertil Steril, 2002;78:637-638.

58. Sentilhes L, Kayem G, Ambroselli C, Provansal M, Fernandez H, Perrotin F, et al.
Fertility and pregnancy outcomes following conservative treatment for placenta accreta. Hum Reprod, 2010; 25:2803-2810.

59. Alanis M, Hurst BS, Marshburn PB, Matthews ML. Conservative management of placenta increta with selective arterial embolization preserves future fertility and results in a favorable outcome in subsequent pregnancies. Fertil Steril, 2006; 86: 1514.e3-1514.e7.

60. Timmermans S, van Hof AC, Duvekot JJ. Conservative management of abnormally invasive placentation. Obstet Gynecol Surv, 2007;62:529-539.

61. Zhang C, Li H, Zuo C, Wang X. Retrospective analysis: Conservative treatment of placenta increta with methotrexate. J Obstet Gynaecol Res, 2018; 44(5):907-913.

62. Palacios Jaraquemada JM, Pesaresi M, Nassif JC, Hermosid S. Anterior placenta percreta: Surgical approach, hemostasis and uterine repair. Acta Obstet Gynecol Scand, 2004; 83:738-744.

63. Mei J, Wang Y, Zou B, Hou Y, Ma T, Chen $\mathrm{M}$, et al. Systematic review of uteruspreserving treatment modalities for abnormally invasive placenta. $J$ Obstet Gynaecol, 2015; 35: 777-782.

64. Pather S, Strockyj S, Richards A, Campbell N, de Vries B, Ogle R. Maternal outcome after conservative management of placenta percreta at caesarean section: A report of three cases and a review of the literature. Austr NZ $J$ Obstet Gynaecol, 2014; 54: 84-87

65. Kabiri D, Hants Y, Shanwetter N, Simons M, Weiniger CF, Gielchinsky Y, et al. Outcomes of subsequent pregnancies after conservative treatment for placenta accreta. Int J Gynaecol Obstet, 2014;127:206-10.

66. Sentilhes L, Kayem G, Ambroselli C, Provansal M, Fernandez H, Perrotin F, et al. Fertility and pregnancy outcomes following conservative treatment for placenta accreta. Hum Reprod, 2010; 25(11): 2803-2810.

67. Lin $\mathrm{K}$, Qin $\mathrm{J}, \mathrm{Xu} \mathrm{K}, \mathrm{Hu} \mathrm{W}$, Lin $\mathrm{J}$. Methotrexate management for placenta accreta: A prospective study. Arch Gynecol Obstet, 2015;291: 1259-1264. 
68. Steins Bisschop CN, Schaap TP, Vogelvang TE, Scholten PC. Invasive placentation and uterus preserving treatment modalities: A systematic review. Arch Gynecol Obstet, 2011; 284:491-502.

69. Fazari ABE, Aristondo MER, Azim F, Al Maamari BA, Eltayeb R. Methotrexate in management of Morbidly Adherent Placenta at Latifa Hospital, DHA, Dubai, UAE.: Case report. Clin J Obstet Gynaecol, 2019; 2: 090094.

70. Matsubara S. Measures for peripartum hysterectomy for placenta previa accreta: avoiding uterotonic agents and "double distal edge pickup" mass ligation. Arch Gynecol Obstet, 2012; 285(6):1765-1767. 